\title{
O BALEIRO DA IDENTIDADE: SUXEITO, TEMPO E NACIÓN EN ROBERT MUSIL
}

Ramón Máiz

Universidade de Santiago de Compostela

DOI: 10.17075/iftpc.2021.006

A Jacobo Muñoz (1942-2008)

In memoriam 

[A] quela foi a Idade de Ouro da seguridade [...]. Naquel vasto imperio todo ocupaba o seu lugar, firme e inmutable. Ninguén pensaba nas guerras, nas revolucións nin nas subversións. Todo o radical e violento semellaba imposible naquela era da razón.

Stephan Zweig, Die Welt von Gestern

Foi entón cando vin de súpeto o meu vello amigo Franz Tunda, trinta e dous anos, san e espelido, mozo e forte, cheo de talento; alí estaba, no centro da capital do mundo, sen saber que facer. Non tiña profesión, nin amor, nin alegría, nin esperanza, nin ambición, nin sequera egoísmo. Ninguén no mundo era tan superfluo coma el.

Joseph Roth, Flucht ohne Ende

Naquela altura non soamente aumentara a aversión moral contra os concidadáns até constituír un verdadeiro sentimento colectivo; había algo máis: a desconfianza fronte a un mesmo e o propio destino acadara a dimensión dunha fonda certeza [...], dun espazo baleiro e invisible no interior do cal se atopaba a realidade, como unha pequena cidade dun xogo de construción para nenos, abandonada pola fantasía.

Robert Musil, Der Mann ohne Eigenschaften

Viver é ser outro. Nem sentir é possível se hoje se sente como ontem se sentiu: sentir hoje o mesmo que ontem não é sentir - é [...] ser hoje o cadáver vivo do que ontem foi a vida perdida.

Fernando Pessoa (Bernardo Soares), Livro do Desassossego

A inacabada «novela» -no sentido de Lukács: «epopea do mundo abandonado polos deuses» (Lukács 2016: 117)- ensaio, palimpsesto reescrito durante máis de corenta anos por Robert Musil (1880-1942), O home sen particularidades (Der Mann ohne Eigenschaften), semella contar una vida. A dun home, Ulrich, sen «atributos», sen «propiedades» de seu, no sentido que precisaba Valverde (1990: 174); isto é, un ser humano sen particularidades propias, un deses personaxes, 
que diría Rezzori, "plurais e proteicos, acosados pola historia universal, que perden e deixan continuamente fragmentos do propio "eu" entre os refugallos da vella Europa» (Rezzori 1993: 8). Pero este libro enxerga ademais, ao fío dos derradeiros momentos do Imperio Austrohúngaro (1913-1914), non só un retrato da época de entre as guerras, senón unha requintada crítica filosófica, estética e política dos fundamentos culturais da modernidade. Atopámonos ante un texto, monumental na súa complexidade, sobre a perda do ethos individualista tardoburgués sen ilusión ningunha de salvación ou consolo, en consonancia con aquel «experimento do mundo» de entre as guerras, «unha grande epopea antiépica da nosa civilización» (Magris 1971: 283; Rogowsky 1994: 146). Da excepcional magnitude deste cumio literario, do seu extraordinario alento de opera aperta, inabordable e, por cabo, imposible, dá conta o longo e descontinuo itinerario da súa (re)escrita: comezada a finais de 1898, mudou varias veces radicalmente de ideas, personaxes e tramas (Hickman 1991: 133-166) antes de o autor ver publicada a primeira parte en 1930 e a segunda, malgré lui, en 1933. Aínda se publicarían despois da súa morte varios capítulos inéditos en 1943 e, finalmente, en 1952 aparecería a edición de referencia de Adolf Frisé (Musil, 1953 e 1978).

Nesta obra amoréanse vectores epocais varios: desde a desintegración (Untergang) do Imperio Austrohúngaro e a emerxente cuestión das nacionalidades, por unha parte, até as excepcionais achegas da nova «cultura da crise» que se desenvolve na Viena de fin de século, de inmenso alcance intelectual, académico e político, por outra (Marramao 1977). Un tránsito convulso do mundo antigo ao moderno e deste último á modernidade serodia que, alén de pesimismo ou optimismo ningún, dá cumprida conta das falsas solucións que se erguen no horizonte da época. Debedor dun extraordinario, único na súa riqueza intelectual, en rigor «irrepresentable» (Magris 1982: 80) contexto político e cultural da Viena fin de siècle, cómpre comezar, ante todo, por lembrar a posición de Musil no espazo de «interacción creativa dos círculos intelectuais» da Viena da época (Timms 1986: 8) (ver figura 1). Alí superpóñense as súas débedas con Mach, 
sobre quen fixo a súa tese de doutoramento na Universidade de Berlín a principios de século; con Wittgenstein, Kraus, Schnitzler, Freud, Bauer ou Hoffmansthal..., mais tamén Rilke ou Nietzsche, este último omnipresente na súa obra por boca da súa personaxe Clarisse (Cacciari 1980: 88; Casals 2003: 223). A constatación dunha fenda irreparable entre unidade e fragmentación, quer individual, quer colectiva, desenvólvese cuns acenos tan cáusticos, tan pouco morriñentos, que ben podería aplicarse a Musil aquel dictum nietzscheano a prol de desbotarmos dunha vez as biografías de «O señor X e o seu tempo» e decantármonos por aqueloutras: «O señor X, loitador contra o seu tempo». Se non esquecido, certamente pouco lido nos nosos días, Musil, Invalid des Lebens (Roth), deveu unha sorte de uomo postumo, e non só como destemido autor daquelas «páxinas póstumas escritas en vida» (Cacciari 1980: 22).

Pero cómpre tamén non deixarse engaiolar pola claridade feliz do «mito habsbúrxico», da benévola saudade polo Finis Austriae, polo «mundo de onte», pola idealización da «familiar síntese dunha harmoniosa multiplicidade» (Magris) na Vienna fin de siècle (Latraverse e Moser 1988; Molnar e Reszler 1989). Conxuntura histórica celebrada en ocasións como deturpada fröhliche Apokalypse, tan lonxe do que por isto entendía Hermann Broch (Broch 1984: 59), apocalypse joyeuse nos termos da mostra parisiense do Centre Georges Pompidu (Clair 1983). Nostalxia do bos e vellos tempos do Imperio contra a que Magris ou Cacciari xa avisaran con lucidez no seu día (Magris 1963; Cacciari 1980) para reivindicaren en toda a súa acuidade os efectos da perda de fundamentos (fundamentum veritatis, Grund), da imposibilidade de seguir postulando «nós, os suxeitos», neste «drammatico incrocio di eventi e di direzioni diverse» (Cacciari 1980: 231).

Así e todo, nos anos finais do Imperio, o conxunto daquela inmensa e heteroxénea «Kakania», por dicilo en termos de Robert Musil, «imperial e real» (kaiserlich und königlich), desde a propia Viena até a cidade de «B.» en Moravia (Brünn, Brno), na que o autor viviu a súa xuventude, converteuse, se non naquela Versuchsstation des Weltuntergangs («estación meteorolóxica da fin do mundo»), 
en luminosa expresión de Karl Kraus, nunha tensa e creativa encrucillada artística, intelectual e política. Un escenario desbordante de conflitos e antagonismos nos que agromaban quer a tensión entre o expresionismo máis radical do prístino «eu» e o esfarelamento deste último no inconsciente e o preconsciente freudianos, quer a tensión entre os nacionalismos máis esencialistas e o feble e, por cabo, perdedor latexo dunha "conciencia supranacional» (Schorske 1979; Janik e Toulmin 1973: 42). Friedrich Hebbel definírao con acerto como «un pequeno mundo que serve de banco de probas para o mundo enteiro» («eine kleine Welt, in der grosse ihre Probe hält») (Fëjto 1990: 108).

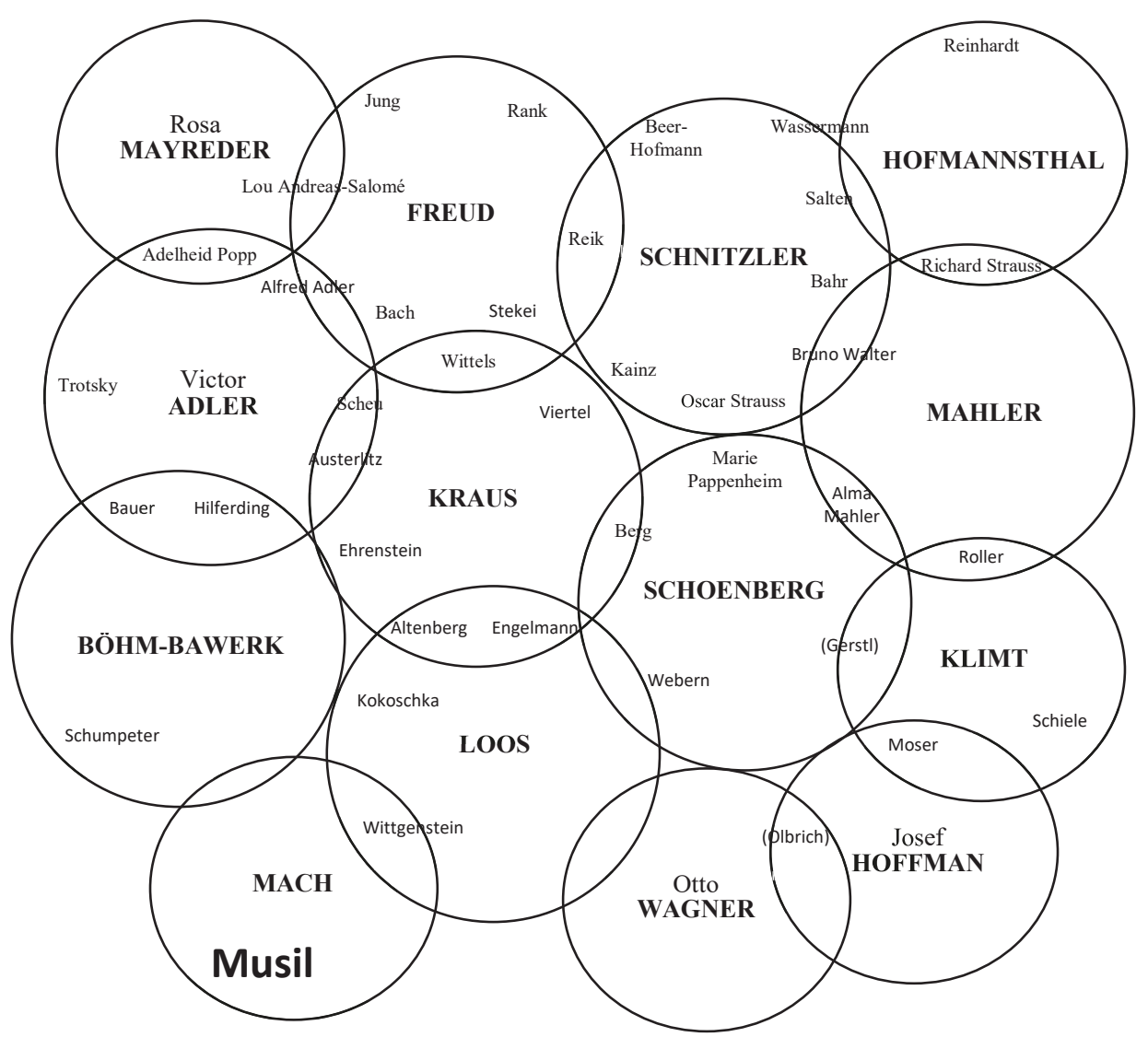

Figura 1: Os círculos intelectuais de Viena e a súa interacción arredor de 1910 (fonte: elaboración propia a partir de Timms 1986) 
Neste capítulo imos apuntar, brevemente, tres aspectos que se atopan en estreita conexión interna e conceptual na crítica da modernidade na obra de Musil e que consideramos capitais para unha cabal lectura de $O$ home sen particularidades desde as preocupacións culturais, quérese dicir políticas, propias da nosa condición tardomoderna: 1) a crítica da concepción linear e continua do tempo e da historia; 2) a cuestión da crise da subxectividade individual e do suxeito moderno, e 3) a imposibilidade dunha identidade colectiva baseada na nación, quer desde o Estado, quer contra o Estado, como unánime totalidade orgánica. Tendo en conta que as novelas de autoformación resultan ao mesmo tempo fazaña do heroe e relato dunha nación subxacente como persona ficta e constitúen auténticas alegorías nacionais -coma se o "eu» protagonista agromase soamente na medida en que se ve recoñecido nun «nós», nunha comunidade de destino e de sentido (Máiz 2007: 15)-, o esfarelamento das identidades individual e nacional no período de entre as guerras prolóngase non xa na carencia de estrutura narrativa e de identidade dos personaxes e da propia Kakania, senón mesmo na imposibilidade última da novela e o seu carácter inexorablemente inconcluso. Para a nosa análise acudiremos tanto a $O$ home sen particularidades, na edición definitiva de Frisé (1978), xunto coa excelente versión española de Pedro Madrigal (Madrigal, Sáenz e Formosa 2010), como aos ensaios e conferencias do autor publicados por Frisé (Musil 2000), botando ocasionalmente man dos Diarios 1899-1941/42 en tradución, tamén excepcional, de Elisa Renau (Musil 1994).

En primeiro lugar, $O$ home sen particularidades cuestiona por completo a concepción linear da historia enxergando unha narrativa da descontinuidade radical. Isto faise dun xeito específico, a saber: articulando dous tempos ben diferentes (Jonsson 2000: 143), que son un tempo cronolóxico e un tempo espacializado e fracturado. O tempo cronolóxico da sucesión dos acontecementos que preceden a I Guerra Mundial e que transcorren na novela a partir do verán de 1913 («Era un fermoso día de agosto do ano 1913...») até o estalido da Gran Guerra. Esta última érguese ameazante como horizonte de expectativas 
do lector e lévao a agardar que o protagonista Ulrich sexa engulido finalmente, dun ou doutro xeito, polo mesmo maelstrom bélico que Hans Canstorp na montaña máxica de Thomas Mann. Nesta dinámica temporal, os acontecementos biográficos dos protagonistas, económicos (capitalismo, explotación, mercadoría, competición) e políticos (vicisitudes do Imperio Austrohúngaro, nacionalismos de Estado e reclamacións das nacionalidades), teñen un peso decisivo. Velaí, por exemplo, a evolución profesional de Ulrich (matemático, enxeñeiro etc.), os recordos infantís en Brno ou a axitación a prol dun nacionalismo integral para Kakania na trama da Acción Paralela que vertebra o primeiro volume da novela. O segundo é un tempo ben diferente, un presente continuo e espacializado, composto por distintos eventos, acontecementos, accións e perspectivas de imposible coherencia e sutura nun tempo linear no que se esvaen as biografías, os acontecementos históricos e as identidades. Pero, destes dous fíos temporais, o tempo linear está sempre subordinado ao tempo espacializado, ao presente continuo que acubilla diversas perspectivas e niveis de realidade, e tamén infinitas posibilidades de que «todo poida acontecer doutra maneira».

Esta tensión entre os dous tempos diferentes é unha achega fundamental do texto que se reflicte na tensión entre dúas narrativas, ou, mellor dito, entre a narración e a súa imposibilidade; o autorrecoñecemento de Ulrich, por unha banda, e a imposibilidade de manter un fío condutor da súa vida, da súa identidade como Ulrich, a sistemática desidentificación ou misrecognition do protagonista, a imposibilidade de dar cumprida conta propiamente biográfica de si mesmo, pola outra. Desde a óptica desta segunda temporalidade, $O$ home sen particularidades constitúe o relato da autenticidade imposible dun home inacabado, sen centro que o unifique, en permanente construción. Como lle confesa Ulrich a Agathe na segunda parte da novela:

Ao lembrar os meus primeiros anos, vexo que apenas estaban desenvolvidas aínda as nocións de interioridade e exterioridade. Cando me achegaba a un obxecto, este viña voando cara a min; e, cando acontecía algo de relevo para nós, non eramos os únicos en emocionarnos, senón que as cousas mesmas comezaban a rebulir... Non nos posuïamos 
a nós mesmos; en realidade, aínda non chegaramos a ser; os nosos estados persoais aínda non se diferenciaban con claridade dos do mundo exterior, semellaba que non estabamos totalmente metidos no noso propio ser. E, o que resulta máis sorprendente, poderiamos afirmar que naquela altura non estabamos totalmente distanciados de nós mesmos. Coa observación, conseguirás no mellor dos casos ir detrás de ti mesma, nunca entrar en ti mesma. Sempre remaneces fóra de ti [«Du bleibst ausser dir»]. Hoxe, cando cres estar en plena posesión de ti mesma, pregúntaste excepcionalmente quen es ti en realidade. Pois ben, chegarás a este descubrimento: sempre te verás desde fóra como un obxecto [...]. En compensación polo feito de sermos adultos, conseguimos pensar «eu son» en calquera momento e sempre que queiramos [...]. En canto acadaches unha "personalidade» [Persönlichkeit] propia, todo o que tocas resulta petrificado até o máis fondo de ti mesma e o único que fica é un fío fantasmal e bretemoso de autoconciencia e amor propio. (Musil 2010: 902)

Esta identificación sempre en precario, sempre deconstruída, promove o efecto de que Ulrich non soamente non sexa quen de dar conta do seu propio pasado, senón tamén de que se vexa imposibilitado de pretender un futuro de seu, un proxecto, unha finalidade, non digamos xa unha realización de proxecto vital autónomo: o "home sen particularidades» é un home sen pasado e sen futuro que vive nunha sorte de eterno presente. En rigor, non hai historia nesta novela, advertiu clasicamente Magris (1963: 308). Blanchot analizouno de xeito inmellorable na súa obra Le Livre à venir:

\begin{abstract}
A historia, tal e como a representamos e cremos vivila, como unha sucesión de incidentes tranquilamente linear, non expresa máis que o noso desexo de nos remitirmos a cousas sólidas, a acontecementos incontestables que se desenvolven nunha orde determinada; a arte narrativa realza o valor desta ilusión tan atraente e benefíciase dela. Mais Ulrich xa non é quen de gozar desta felicidade da narración sobre cuxo modelo se constitúen séculos de realidades históricas. (Blanchot 1959: 171)
\end{abstract}


A «vida» para Ulrich, en apenas o lapso dun ano (1913-1914) que abranguen as máis de dúas mil páxinas, constantemente reelaboradas, da novela, constitúe unha experiencia descontinua e fragmentada, «irregularidade, cambio, períodos, fracasos en manter o camiño, colisión de obxectos e intereses» (Musil 2010: 47). Máis que dunha «vida», semella tratarse, por dicilo con palabras de Roland Barthes no seu Michelet, dunha «rede organizada de obsesións» que deriva reiteradamente en ensaio sobre problemas varios con multiplicidade de perspectivas e puntos de vista en debate constante, que o autor asume consciente dos seus riscos: «Perigo: enlearme na teoría», «Demasiadas ideas: convirto cada capítulo nun imposible» (Casals 2003: 334). Soma Morgenstern conta no seu libro de recordos Huida y fin de Joseph Roth o que este último lle dixo tras unha acalorada discusión con Musil no Café Museum de Viena: «Fala como un austríaco, mais pensa como un alemán. Como os teus amigos Benjamin ou Bloch. Nada máis que filósofos» (Morgenstern 2000: 115).

Podemos observar, nesta orde de cousas, como no devalar da novela agroman polo menos tres características que rachan coa concepción moderna do tempo; en concreto, espacialización, atemporalización e presentificación da experiencia e a realidade. $\mathrm{O}$ abandono do tempo linear e continuo e o seu correlato, o mito do "Progreso», articúlase coa sensación xa comentada da perda do pasado e do futuro, xerando un presente continuo; poderíase falar incluso dun tempo atemporal, tomando prestado o concepto de Castells. Esta instantaneidade, por dicilo así, vai ben máis alá da presentificación, pois prolóngase ademais nunha pluralidade irredutible de presentes perpetuos e múltiples, nunha compresión do tempo que se volve conflito e non-correspondencia entre aqueles presentes múltiples. Fronte á febril procura da memoria, de raíces, de fundamentos históricos, predomina na novela unha sorte de amnesia cronificada. Fronte a calquera pretensión de permanencia e duración, os personaxes do libro desprázanse nun espazo-tempo de efémera fugacidade. Espacialización e destemporalización van da man, en terceiro lugar, cun plural abano de temporalidades concorrentes e provistas de lóxicas diferentes que constrúen non unha utopía, na que a crítica 
adoita insistir, senón, por dicilo con Foucault, unha heterotopía, un espazo heteroxéneo de procesos, identidades, lugares e relacións ensarillados ao chou. A «realidade» neste poderoso texto, verdadeira antítese da novela de formación, non só se esnaquiza e se fragmenta, senón que ademais actualiza unicamente algunha das súas infinitas posibilidades potenciais (Magris 1963: 302). En consecuencia, esváense perante o lector as características fundacionais da historia moderna como fazaña da liberdade, nomeadamente a existencia dun pasado real, cognoscible e considerado como depósito da evolución e do progreso das ideas e das institucións; a posibilidade mesma da obxectividade científica como Verdade única (para Musil, «es gibt Wahrheiten, aber keine Wahrheit»), dun relato único como cerna da identidade quer individual, quer colectiva das nacións e dos Estados; a asunción de que a Razón faculta unha explicación causal en sentido forte do pasado, e, por cabo, a concepción do papel da historia como magistra vitae e transmisión do herdo cultural dunha xeración a outra (Cadro 1).

A perda da orde narrativa da novela, a imposibilidade mesma de remate do libro por parte do autor, o distanciamento dos canons novelísticos do realismo e do Bildungsroman, o esnaquizarse daquela clásica anagnórise do heroe acadan un nivel en Musil só comparable ao que podemos atopar en Proust, Döblin ou Mann, e sobre todo en Os somnámbulos e $A$ morte de Virxilio, de Hermann Broch, ou no Ulysses de James Joyce. Repárese, por exemplo, no capítulo 122, titulado «Heimweg» («De camiño á casa»), no que se constata abertamente que «a narración devén imposible», por dicilo con palabras posteriores, pero aquí pertinentes, do nouveau roman (Robbe-Grillet). Lemos, en efecto, a voz do narrador manifestando o seguinte: «Os homes, nas súas fundamentais relacións consigo mesmos, son na súa maioría narradores [...]; gustan da sucesión ben ordenada dos feitos porque semella unha necesidade; e, grazas a que a súa vida lles parece un "curso" [Lauf], séntense acubillados dalgunha maneira no caos». O propio Ulrich decátase de que «todo se volveu inenarrable e a vida xa non segue ningún "fío" [Faden], senón que se estende no espazo dunha superficie infinitamente entretecida» (Musil 2010: 650). Este é o horizonte de toda unha 
época, en palabras de Schnitzler no seu Paracelsus: "Soño e vixilia, verdade e mentira conflúen un enriba doutro. Non hai seguridade por ningures» (Gay 2002: 21).

Cadro 1: Dimensións modernidadelmodernidade serodia en Robert Musil e O home sen particularidades (fonte: elaboración propia de R. Máiz)

\begin{tabular}{|c|c|}
\hline Modernidade clásica & Modernidade tardía \\
\hline Tempo linear e continuo, pasado-futuro, nostalxia & $\begin{array}{l}\text { Tempo atemporal, presentificación, } \\
\text { presentes perpetuos e múltiples, descontinuidade }\end{array}$ \\
\hline Memoria, experiencia, permanencia, expectativas & $\begin{array}{l}\text { Amnesia, espacialización, destemporalización, } \\
\text { fugacidade }\end{array}$ \\
\hline Kronos & Kairós \\
\hline Risco, determinación & Incerteza, apertura, indeterminación, alteridade \\
\hline Utopía & Distopía, heterotopía \\
\hline $\begin{array}{l}\text { Subxectividade, identidade, ipseidade, } \\
\text { unidade psíquica, esencia, raíces, pertenza }\end{array}$ & $\begin{array}{l}\text { Alteridade, fragmentación, ausencia, baleiro, } \\
\text { negatividade, constitución simbólica do «eu», } \\
\text { proceso, Ichlosigkeit, Möglichkeitssinn }\end{array}$ \\
\hline $\begin{array}{l}\text { Vangarda, crítica, experimentación lingüística, } \\
\text { expresionismo }\end{array}$ & Parodia, ironía, construtivismo \\
\hline Estilo & Alusión, intertextualidade \\
\hline $\begin{array}{l}\text { Bildungsroman, estrutura narrativa, } \\
\text { narrador omnisciente }\end{array}$ & Dislocación, ensaio, pluralismo de perspectivas \\
\hline Significación, significado & Significante flotante \\
\hline Hipotaxe, metáfora, hipérbole & Parataxe, metonimia, metalepse \\
\hline Teleoloxías emancipatorias, metanarrativas & Escepticismo, cinismo \\
\hline Gran narrativa, metarrelato & Deconstrución, estética \\
\hline Ética, crítica, denuncia & Estética, relativización, afastamento moral \\
\hline Heroe & Antiheroe \\
\hline Monismo & Pluralismo \\
\hline Universalismo, Ciencia, Verdade & $\begin{array}{l}\text { Particularismo e universalismo, Ciencia e poesía, } \\
\text { «verdades», contextualismo, «ideoloxía» }\end{array}$ \\
\hline $\begin{array}{l}\text { Nación, cultura, raza, comunidade, } \\
\text { territorialidade }\end{array}$ & $\begin{array}{l}\text { Heimatlosigkeit, identidades plurais, líquidas } \\
\text { e superpostas, extraterritorialidade }\end{array}$ \\
\hline Goethe: Wilhelm Meister & Broch: Der Tod des Vergil, Die Schlafwandler \\
\hline
\end{tabular}


Agora ben, todo o devandito nos remite a un segundo tema da novela, que agroma, como vimos, ao fío da temporalidade: a espacializacion do tempo, así como a súa presentificación, prolónganse nunha concepción da subxectividade que se ergue en figura epocal da obra, isto é, Ulrich, o home sen particularidades propias, ou, tanto ten, de propiedades sen home (Musil 2010: 608): «¿Non é certo que as experiencias se independizaron dos seres humanos? [...] Velaí como agromou un mundo de propiedades sen homes ["eine Welt von Eigenschaften ohne Mann”]». Un mundo de experiencias sen ninguén que as viva. En forzada e impensable síntese de Mach e Nietzsche, Musil non deixa o autor, nin o protagonista, nin tampouco o lector, instalados nun lugar soberano ollando con señorío desde o trono do horizonte de expectativas: «[A] descomposición das relacións antropocéntricas, que durante tanto tempo consideraron o ser humano como o centro do universo, pero que desde hai séculos están desaparecendo, chegou finalmente até o propio "eu”" (Musil 2010: 150). Ulrich, aos seus 32 anos, só sabe de si mesmo que "para el non hai nada firme», "está situado nun punto equidistante de todas as particularidades e todas elas, tanto se se apropiase delas coma se non, resúltanlle, dun modo estraño, por completo indiferentes» (Musil 2010: 151).

Velaí a razón última das tensións constitutivas do protagonista como home sen particularidades, entre exactitude e alma («aquilo que foxe en canto oe falar de progresións alxébricas»), ciencia e poesía, o «ratioide» e o «non-ratioide». Ulrich, cambiando de rumbo constantemente ao fío da súa peripecia vital (militar, matemático, enxeñeiro...), carece de «atributos», de «particularidades propias», de «carácter», de «personalidade». Non se albiscan puntos de referencia persoais minimamente sólidos: nin clase, nin Bildung, nin familia, nin patria, nin destino; en suma, sen raíces e sen futuro, sen áncora de salvación e perdido, á toa nun «estado de permanente provisionalidade» (Casals 2003: 317). Como o Franz de Fuga sen fin, de Joseph Roth: «[A]lí estaba, no centro da capital do mundo, sen saber que facer». Por iso Ulrich «odia a morte todo o que aparenta ser inamovible, os grandes ideais, as leis e a súa pequena pegada petrificada, o 
carácter pacífico. Non considera nada firme, ningún eu, ningunha orde [...], non cre en ataduras e todo posúe un valor que soamente dura até o seguinte acto de creación, como un rostro ao que se fala e que cambia a cada palabra» (Musil 2010: 154). Rendición de contas de toda unha época a través da súa versión petrificada no Imperio Austrohúngaro, presidida polo vello emperador inmortal, o déspota benevolente que Roth describe con agarimosa indulxencia en $A$ marcha Radetzky. Pero, a diferenza de Roth, como subliñou de forma maxistral Magris, «[p]iù che sul momento malinconico, Musil insiste ovviamente su quello ferocemente dissolutore» (Magris 1963: 304).

E isto acontece desde o propio comezo do libro, no capítulo 1: «Musil lémbralle ao lector desde o principio que, simplemente, o cosmos de Goethe nesa altura xa non existe» (Luft 1980: 219). Aquel ábrese con dous acontecementos impersoais, un informe meteorolóxico dun día de finais de agosto de 1913 e unha descrición do tráfico incesante nunha gran cidade. Nada atopamos de contexto, de raíces familiares, de historia colectiva, de socioloxía realista nin de análise psicolóxica dos personaxes: os asuntos humanos, na perspectiva de Musil, dependen dunha mera coincidencia de feitos amoreados ao chou... Escenas anónimas nas que se albiscan como sombras dous personaxes igualmente anónimos «tratados de xeito impersoal [...][,] cuxa identidade é tan só suxerida para ser negada» (Hickman 1991: 136).

Resulta de interese, para estes efectos, comparar o tratamento da tradición familiar en $O$ home sen particularidades e $A$ marcha Radetzky. Esta última está presidida en todo momento polo retrato do avó, o heroe de Solferino que dá continuidade ao Imperio, ao tempo que ás sucesivas xeracións dos Trotta: «Todos os anos, durante as vacacións de verán, tiñan lugar os mudos diálogos entre o neto e o avó» (Roth 2020: 57). Nun rexistro moi diferente, descríbesenos a Ulrich:

[M]irou o seu pai á cara. Posiblemente todo o que consideraba unha peculiaridade persoal propia non era máis que unha contradición dependente daquel rostro, adquirida nalgún momento da infancia [...]. Buscou nel algunha semellanza. Poida que as houbese. 
Quizais todo estivese alí, a raza, a obriga, a personalidade, a corrente do herdo, do cal un mesmo non é máis que unha onda, unha limitación, un desalento, a eterna reiteración e movemento circular do espírito. Todo aquilo que odiaba no máis fondo da súa vontade de vivir. (Musil 2010: 693)

Velaí o complexo «austríaco» sobre o que Musil traballa: a Selbstentfremdung, a autoalienación, a autenticidade imposible, a culpable conciencia de infidelidade a un mesmo por mor da infidelidade á historia, a imposibilidade de reconducir as peripecias do protagonista a un vector organizativo e coherente. Pero non é iso, por caso, o que significa historicidade? Unha paisaxe de descontinuidade, fracturas, «cesuras epocais» fronte ao mito das Orixes, correlato indispensable da función fundadora do Suxeito moderno e as súas propiedades: continuidade, esencia, sentido, verdade. A única posibilidade que se soergue é a dunha condición desnortada, un "estado non vectorial»: "Xa non existe un home completo fronte a un mundo completo, senón un algo humano ["ein menschliches Etwas"] que se move no seo dun xenérico fluído nutriente» (Musil 2010: 217). Por iso Agathe lle di a Ulrich nun determinado momento, con aterradora lucidez: "Cando falas comigo [...] é coma se me estivese mirando nos anacos dun espello roto; contigo resulta imposible verse de corpo enteiro». «Non -retrucou Ulrich sen soltarlle a man-; hoxe en día, un non pode verse nunca de corpo enteiro, nin é posible tampouco moverse con todo o corpo á vez» (Musil 2010: 684).

O home sen particularidades argalla, desde estas premisas, unha concepción antiesencialista da subxectividade; isto é, desbota radicalmente a idea de que os seres humanos posuímos unha substancia, un núcleo duro particular expresado na nosa raza, nación, cultura, sexo ou clase social. Pola contra, para Musil o ser humano caracterízase pola ausencia -«mon admirable absence», que diría Blanchot en Thomas l'Obscur- de todo núcleo duro interior: "Non hai substancia, nin identidade, subxacente ao que chamamos "eu", ego, individuo, suxeito. Tan só un fluxo de elementos impersoais». O noso autor reformula para os seus pro- 
pósitos o concepto de Mach -sobre o que, recórdese, fixo a súa tese de doutoramento en 1908 en Berlín- de Ichlosigkeit, de disolución e perda do «eu». Como en $A$ morte de Virxilio ou en Os somnámbulos, de Hermann Broch, en $O$ home sen particularidades a subxectividade non está determinada nin pola esencia da liberdade interior nin pola sociedade, senón que flúe nun Zwischenraum atemporal, heterolóxico e múltiple. Para Musil o dilema entre universalismo e particularismo, entre as teses liberais -isto é, a existencia dunha esencia universal independente da sociedade, a cultura e a clase- e a alternativa comunitarista -isto é, o ser humano como enraizado nunha raza, unha cultura, unha nación, e debedor delas-, é un falso dilema. A universalidade, se acaso, reside na negatividade, na outredade, no anderer Zustand ou "condición de alteridade» (Musil 2010: 365). Musil desenvolve e precisa o concepto desta peculiar condición vital no seu capital ensaio Der deutsche Mensch als Symptom ( $O$ home alemán como sintoma, 1923), sobre o que logo imos volver para outros efectos:

Posuímos moitísimas descricións da condición de alteridade. O común a todas elas podería ser que os límites entre o Eu e o Non-Eu resultan menos nidios do que se presupón habitualmente e mesmo se dá unha certa inversión na súa relación mutua [...]. Mentres damos por suposto que o Eu domina o mundo, na condición de outredade o mundo desemboca no Eu e mestúrase con el ou transpórtao ou cousas semellantes. (Musil 2000: 1393)

En palabras de Jonsson, «[a] transgresión da orde temporal e a subversión irónica das matrices discursivas contribúen á xeración dun espazo de indeterminación e potencialidade que disolve a mimética representación dun carácter vital movéndose a través dunha realidade externa sólida» (Jonsson 2000: 126).

Hai un fragmento en $O$ home sen particularidades que resulta especialmente iluminador para o que aquí nos ocupa: 
Un paisano posúe polo menos nove caracteres: profesional, nacional, estatal, de clase, xeográfico, sexual, consciente, inconsciente, privado [...] e, sobre todo [...], un décimo carácter: a fantasía pasiva dos espazos baleiros. Este carácter permítelle ao ser humano todo agás unha cousa: tomar en serio o que significan os outros nove caracteres [...], un espazo baleiro e invisible en cuxo interior está a realidade, como unha pequena cidade de pedra dun xogo de construción para nenos, abandonada pola fantasía. (Musil 2010: 34)

Un baleiro identitario [...] que constitúe o auténtico pregamento da nosa realidade, o lugar invisible dunha identidade que escapa mallada das aventuras da razón autosubstanciada do ideal da modernidade. (Bayón 2009: 259)

Non por casualidade, o inicial nome de Ulrich foi Anders -o Outro-. E é que, efectivamente, o seu «eu» constitúe un baleiro: «un círculo grande, baleiro, redondo»-por iso é un home «sen carácter»-, tan só «un substituto de emerxencia para algo que está perdido» (Musil 2010: 384); no mellor dos casos, por dicilo con Barthes, «un Je de papier». O seu amigo Walter, a súa antítese como dramatis persona, defíneo con inmellorable precisión:

-É un home sen particularidades.

-E que é iso? -preguntou Clarisse [...].

-Nada. Sinxelamente nada [«Nichts. Eben nichts ist das»].

(Musil 2010: 64)

Hai tempo que Blanchot definiu esta «nada» de $O$ home sen particularidades, esta «singolarità qualunque», que diría Agamben, con palabras que escusan ulterior comentario por premonitorias: «C'est l'homme quelconque, l'homme sans essence, l'homme qui n'accepte pas de se cristalliser en un caractère, ni se figer en une personnalité stable» (Blanchot 1959: 169).

Velaí a centralidade da personaxe de Agathe, por mor da súa natureza especular na construción da precaria subxectividade do protagonista, o dobre feminino de Ulrich, e por tal motivo o extraordinario relevo da segunda parte da novela, 
que, desbotada a miúdo como secundaria narración dun amor incestuoso, devén decisiva para unha cabal comprensión do primeiro volume. Velaí o «outro eu» de Ulrich, cuxa identidade se constrúe non mediante un proceso evolutivo de autorrecoñecemento e procura de autenticidade, senón na mutua negación de toda identidade que veña dada de antemán. Particularmente salientable resulta o fragmento de comezos do libro segundo («Vertrauen») no que Ulrich olla para Agathe:

Contemplou o rostro dela mentres falaba [...]. Aquela faciana inquietábao por algunha razón. Por cabo decatouse de que, simplemente, non podía identificar o que expresaba. Naquela faciana faltaba algo, aquilo que permite tirar unhas conclusións sobre a persoa. Era un rostro rico en contido, mais nada por ningures estaba subliñado e sintetizado nuns riscos caracterolóxicos como adoita suceder. (Musil 2010: 677)

Agora ben, desta perda da esencia, desta condición eigenschaftlos, da ausencia de calidades, de particularidades propias ou atributos, desta provisionalidade; en fin, desta "nada» agroma un sentido último de posibilidade (Möglichkeitssinn) que se contrapón ao sentido da realidade dun mundo xa cristalizado definitivamente. A continxencia e a indeterminación expanden o horizonte da man da tensión moderna por excelencia entre cuestionamento e establecemento do suxeito (Bürger e Bürger 2001): «[T]odo pode ser verdadeiramente doutra maneira» (Musil 2010: 16). Esta visión crítica da «realidade» como potencialidade, como apertura, continxencia e indeterminación, xera unha oportunidade para ser tratada fóra dos paradigmas da «decadencia» ou o Kulturpessimismus, isto é: «como problema e ficción» (Musil 2010: 16). De aí a teima musiliana de pensar o mundo «como Deus: en subxuntivo potencial» (Musil 2010: 19). En definitiva, en Musil a crítica nietzscheana da racionalidade, por mor do contrapunto científico do que o dota a súa formación, non se prolonga na problemática lukacsiana da destrución da Razón, senón que habilita o alumeamento dun modelo novo para o eventual desenvolvemento dunha forma superior de conciencia intelectual (Hinz 2000: 201). 
Por iso en Musil o suxeito non se esfarela, como diría Foucault, «como un rostro de area na beira do mar»; mais tampouco sinxelamente «desaparece», senón que, como salientou Manfred Frank, nun novo xiro na súa complexa visión do mundo e da vida -recuperando ás agachadas a mística de Eckhart e dos primeiros románticos (Novalis, Schlegel, Schleiermacher e Schelling)-, Musil afástase de Mach nun punto clave: «O decisivo é o feito de que Mach considerase un pseudoproblema metafísico o fenómeno do suxeito humano; isto é, un fenómeno que non existe realmente. Musil sostén, pola contra, que, en efecto, o "eu" se atopa en realidade, como amosou Mach, falto de particularidades propias (sen substancia, sen un núcleo de subxectividade sólido e independente), pero que non por iso se reduce a ser "nada en absoluto", é dicir, mera aparencia» (Frank 2004: 353). Ricœur conclúe: "Que é o “eu” cando o suxeito di que non é nada? Un "eu" privado do auxilio da mesmidade [mêmeté]» (Ricœur 1990: 196).

Agroma aquí unha perspectiva construtivista da subxectividade: «Musil optou polo construtivismo, pola procura de novas linguaxes e novas razóns, por unha vontade de valor que non fose xa máscara da violencia, polo experimentalismo» (Muñoz 1994: XVI). Esta é unha diferenza capital a respecto da diagnose crítica sobre a modernidade en Broch e Musil: neste último, o rexeitamento devén posibilidade de reinterpretación (Martens 2006: 253). Alén de calquera compracente vontade de fragmento e dispersión, de tranquila desesperación no baleiro desa «nada», Musil aposta con decisión por explorar as condicións de posibilidade e, diriamos, de «narratividade» dun suxeito en proceso; por seguirmos a Kristeva, de homme non-assujetti, de homme-procès (Kristeva 1974: 99). De aí a tensión creativa nunca resolvida que se mantén ao fío descontinuo do texto como unha mea sen conda. Por unha parte, un ser humano con propiedades, con «carácter», con "personalidade» resulta hiperidentificado, isto é, mera expresión esóxena dunha raza, nación, clase ou profesión. Por outra banda, un ser humano definitivamente privado de calidades, de particularidades propias, resulta hipersubxectivizado, un ser antisocial e patolóxico. Esta tensión abre a incerta 
oportunidade de ser outro, actualizar algunha das infinitas posibilidades que se albiscan no curso dunha vida, navegar a existencia a barlovento da indeterminación e a continxencia. Pero, ao propio tempo, asumir construírse co outro e como outro. Tal é a misión do segundo libro da man da deconstrución do xénero na modernidade que nel se debulla: «Musil destrúe a doce feminidade vienesa tan cara a Hoffmannsthal e a Schnitzler [...], o verdadeiro, o incorrupto centro poético do mundo de onte» (Magris 1963: 316). Esta é a razón última do complexo xogo de identidade e diferenza entre Ulrich e Agathe -«Ela será quen descubra en min as particularidades»-: un devir «non separados pero non unidos» [«die Ungetrennten und Nichtvereinten»] (Musil 2010: 652); por cabo, «tal é o misterio da irmá: ela é o punto no que todo converxe, a identidade e a alteridade» (Casals 2003: 332).

Abordemos agora o terceiro tema de $O$ home sen particularidades que nos ocupa: a cuestión nacional. Problema que, como imos ver decontado, está en estreita relación interna e conceptual cos dous anteriores (a concepción do tempo e a crise do suxeito moderno). Sosteremos no que segue que a concepción da subxectividade como proceso, así como as dicotomías presentes na novela que xa comentamos -realidade/condición de alteridade, ser humano/particularidades, ciencia/arte (Luft 1980: 218)-, resultan decisivas para dar conta da tensión subxectividade/identidade na elaboración do tema central do fío argumental da novela, que é a identidade colectiva, nomeadamente a identidade colectiva no primeiro plano da política mundial de entre as guerras: a nación. Como subliñou Böhme, «o modelo existencial do home sen particularidades é plenamente válido para Kakania como un todo» (Böhme 1974: 329). Debedora da crise da modernidade que se produce ao abeiro do derrubamento do Imperio Austrohúngaro, existe unha estreita relación entre o tema musiliano da Ichlosigkeit (perda da subxectividade) e da Heimatlosigkeit (perda da identidade nacional). Nin nación inclusiva para o conxunto do Imperio por mor do seu réxime antidemocrático, nin nación cultural alemá que non se torne antisemita e militarista. A nosa hipótese resulta expresada con meridiana claridade por un dos personaxes da novela: 
a Nación devén unha precaria Comunidade de individuos en plena crise de identidade, de desenraizados, de deracinés, unha "Gemeinschaft der vollendet ichlosen» (Musil 2010: 555).

Como se estudou con profundidade (Bringazi 1998), O home sen particularidades non só adopta como un dos seus eixes vertebrais a cuestión nacional na Europa de entre as guerras, senón que, ademais, precisamente presenta o «nacionalismo» como resultado da perda e dilución da subxectividade no mundo tardomoderno, como un expediente para resolver a crise da subxectividade individual mediante a inmersión e asolagamento do «Eu» na totalidade orgánica dun «Nós» da Nación esencial. No demorado devalar das páxinas da novela, en efecto, atópase unha requintada análise dos principais mitos do nacionalismo organicista; en síntese, podemos apuntalos sen pretensións de esgotarmos o tema:

a) O mito da nación como patria (Heimat), no que se exploran as dimensións nativistas do concepto de natio, como lugar de nacemento e de memoria compartida (Vaterland, Muttererde).

b) O mito da nación como comunidade monocultural, pechada na súa Kultur (particularista) fronte á Zivilisation (universalista), non necesariamente formulada a partir das temáticas da decadencia ou o Kulturpessimismus, se ben escindida entre a «alta» cultura das clases dominantes e as formas völkisch das clases populares.

c) O mito da nación como comunidade lingüistica alemá de base, no seo dun imperio concibido como escenario por esencia do conflito lingüístico -«Klassiker Land der Sprachenkämpfe»-; a lingua alemá como elemento diacrítico definidor da nación, destinada á conformación dunha Mitteleuropa panxermánica.

d) O mito da nación como sociedade de masas, exemplificada nas descricións do mundo urbano das metrópoles centroeuropeas (Viena, Berlín) -como non lembrar aquí a Berlin Alexanderplatz de Alfred Döblin-e a soidade compartida na máis absoluta anonimidade (menslichen Gestaltlosigkeit). 
e) E, finalmente, o mito dominante da nación como raza, como factor determinante da «fronteira interior» na formulación propiolalleo, nós/eles, amigolinimigo: arianismo e omnipresente antisemitismo (vulnerado de xeito elocuente pola relación entre os dous criados, Rachel e Soliman).

Agora ben, este complexo mitema nacionalismo-racismo-antisemitismo articúlase de xeito moi complexo nas páxinas de $O$ home sen propiedades sobre tres eixes argumentais: 1) a "Acción Patriótica» ou «Acción Paralela» (Parallelaktion), a campaña a prol da consecución dunha identidade nacional compartida para o Imperio Austrohúngaro; 2) as reivindicacións das nacionalidades internas no seo do Imperio, e 3) os nacionalismos de Estado europeos da época, nomeadamente o nacionalismo alemán e Prusia.

En primeiro lugar, xa que logo, preséntase a temática de «Kakania» vencellando a crise da subxectividade coa crise ou imposibilidade da identidade nacional: "Aquela nación incomprensible e xa desaparecida, que en tantas cousas foi un modelo non suficientemente recoñecido» (Musil 2010: 32). A causticidade de Musil ao respecto desbota calquera señardade ou nostalxia polos tempos idos, que ten varias versións e distintas intensidades, todas elas dunha indiscutible calidade, desde a literatura en perspectiva austríaco-alemá(-xudía) (Roth, Schnitzler, Zweig, Morgerstern, Werfel, Von Rezzori, Von Doderer...) até a húngara (nomeadamente na Triloxía transilvana de Miklós Bánffy). Por ningures atopamos no noso autor sinais dunha mitificación do Imperio:

O Estado afundido [versunken] de Kakania [...] [e]ra [...] imperial-monárquico [kaiserlich-königlich] e foi verdadeiramente «imperial» e «monárquico» [...]. Na escrita chamábase «Monarquía Austrohúngara», na fala común dicíase simplemente «Austria» [...]. Segundo a Constitución, o Estado era liberal, pero tiña un Goberno clerical [...]. Tiña tamén un Parlamento, o cal facía tanto uso da súa liberdade que case sempre estaba pechado; menos mal que había unha normativa do estado de excepción con cuxa axuda se saía de apuros sen precisar do Parlamento. Ante a lei, todos os cidadáns eran iguais, 
pero, por desgraza, non todos eran igualmente cidadáns $[\ldots] .=[\mathrm{N}]$ on só aumentara a aversión contra os concidadáns até constituír un sentimento colectivo; incluso a desconfianza fronte a un mesmo e ao propio destino adquirira unha natureza de fonda certeza. (Musil 2010: 33-34)

Especialmente significativo resulta o tratamento, no capítulo 42, da relación entre os dous compoñentes nacionais subxacentes na bicéfala aiga imperial:

O sentimento estatal [Staatsgefühl] austrohúngaro non estaba formado, como se podía crer, por unha parte austríaca e outra húngara, que se completaban entre si e formaban un todo, senón que o compuñan un todo e unha parte: o concepto de Estado húngaro e o concepto de Estado austrohúngaro, que tiña o seu territorio en Austria, mentres que o concepto de nacionalidade austríaca carecía de patria ningunha. $\mathrm{O}$ austríaco existía soamente en Hungría e, alí, baixo a forma de aversión; [...] deste xeito, autodeclárase «austríaco-máis-un-húngaro-menos-este- húngaro» [...]; de feito, non podía soportar os húngaros, nin os húngaros aos austríacos [...]. Inda por riba había, ademais, polacos, eslovenos ou mesmo alemáns a secas, o cal xeraba novas divisións internas [...]. (Musil 2010: 170).

Todo isto contextualiza a trama da desnortada pretensión da Acción Paralela, liderada por Leinsdorf: «construír a patria», "espallar o auténtico patriotismo» (Musil 2010: 146); realizar, en definitiva, o ideal nacional en Austria-Hungría. A teima de fundar un auténtico "nacionalismo kakaniense» (kakanischer Nationalismus) e dar cumprimento á tese de que "o ser humano só pode atopar o seu pleno e verdadeiro sentido na vida comunitaria dunha nación». Tal era a razón de estar empeñado na idea de formar cos pobos do Imperio un só pobo, unha nación..., pero, «infelizmente, estes insistían en que xa formaban nacións, esixían a restitución dos seus dereitos históricos [...] e afirmaban con descaro que o Imperio era o cárcere do que se querían liberar» (Musil 2010: 452).

Isto lévanos, en segundo lugar, a un dos eixes da estrutura narrativa de $O$ home sen particularidades: a cuestión das nacionalidades. A Acción Paralela tiña 
por obxectivo, precisamente, contrarrestar as reivindicacións de varia intensidade e moi diversa orientación política das once nacionalidades que contiña o Imperio. Nacionalidades que non só tiñan diferentes linguas e culturas (e relixións), senón que, ademais, non podían ser divididas en claras demarcacións territoriais e presentaban grandes desigualdades económicas, como Bauer subliñara na obra de referencia sobre o tema: A cuestión das nacionalidades e a socialdemocracia (Bauer 2020: 342). O problema preséntase desde o comezo con toda crueza: «[A]quelas loitas nacionais que con razón atraeron a curiosidade de Europa [...] por mor de que a aversión que uns cidadáns senten contra as aspiracións doutros [...] se presentou de xeito temperán naquel Estado» (Musil 2010: 36). A estrutura do Imperio non soamente se baseaba na dominación de Austria sobre Hungría e de ambas as dúas sobre outras nacionalidades ou minorías non territoriais, sen esquecer o antisemitismo estrutural e omnipresente, senón que, por cabo, o único vínculo estable entre todas elas non era un acordo político-territorial, un deseño institucional: era a persoa mesma do emperador «pola graza de Deus». Como ironiza Roth en $A$ marcha Radetzky: «Ningunha maxestade de Europa depende tanto da graza de Deus e da fe dos pobos na graza de Deus. O emperador de Alemaña seguirá gobernando aínda que Deus o abandone; reinará, se é necesario, pola graza da nación. O emperador de Austria-Hungría non se pode dar o luxo de que Deus o abandone. Pero agora Deus abandonouno» (Roth 2020: 186). Para desolación dos activistas da Acción Paralela: «[S]e lle preguntaban a un austríaco de onde era, non podía responder, como é natural: son dos "Reinos e provincias representados no Parlamento" que xa non existen; en consecuencia, prefería dicir: son polaco, checo, italiano, friulano, ladino, esloveno, croata, serbio, eslovaco, ruteno, valaco... Velaí o chamado nacionalismo» (Musil 2010: 450). Musil subliña a aporía política do mundo austrohúngaro: ningunha solución á cuestión das nacionalidades era posible sen derrubar o enteiro réxime do Imperio, que portaba na súa cerna a opresión estrutural das nacionalidades. 
[A] política kakaniense das nacionalidades [...] seguía o seguinte método: o Goberno, en ciclos alternos de máis ou menos seis meses, quer procedía a castigar unha nacionalidade insubordinada, quer a respectaba prudentemente [...], e, co paso do tempo, mesmo a «nacionalidade» alemá, que desempeñaba un papel tan importante en Kakania, porque procuraba sempre que o Estado fora poderoso [...], empezou a sentirse nación oprimida! (Musil 2010: 515)

En terceiro lugar, os diferentes personaxes da novela personalizan as principais posicións en conflito arredor da cuestión nacional no Imperio Austrohúngaro (vid. figura 2), superpoñendo de xeito xenial as tres dimensións: imperio, nación e narración. A crise do Imperio e o agromar das desavinzas e loitas nacionais de natureza moi diferente fan imposible a unidade fundacional da novela realista ou do Bildungsroman. Unha imparable polifonía de voces, axencias e heteroxeneidade discursiva que brota contra o discurso dominante do Imperio volve quimérica a forzada monodia do «nacionalismo kakaniense». Nun reconto rápido atopamos as seguintes variantes de nacionalismo sostidas por diferentes personaxes:

a.- Leinsdorf: imperialismo, tardofeudalismo, aristocracia adiñeirada, nacionalismo austríaco-alemán. Influencia de Fichte e os Discursos á nación alemá.

b.- Arnheim: nacionalismo prusiano, panxermanismo, Mitteleuropa alemá, Imperio Alemán (Alemaña mais Austria-Hungría).

c.- Stumm: nacionalismo militarista e racista. Apoloxía da guerra. Preanuncio da anexión (Anschluss).

d.- Leo Fischel: nacionalismo liberal, burguesía, humanismo, minoría xudía.

e.- Gerda Fischel («loira, libre, alemá e forte, que nada tiña que ver cos seus pais»): nacionalismo antisemita e protofascista.

e.- Diotima: nacionalismo cultural, Bildung.

f.- Tuzzi: burocracia do Imperio Austrohúngaro, centralismo estatalista, moderación que cede o paso ao aliñamento proalemán na guerra do 1914 . 
g.- Sepp: xuventude protofascista, nacionalismo alemán racista, antisemitismo, círculo de «estudantes antixudeocapitalistas».

h.- Feuermaul: pacifismo, antibelicismo, cosmpolitismo.

i.- Meingast: militarismo, «soldado da nación», "crueldade executada sistematicamente», antihumanitarismo.

j.- Schmeisser: socialismo, republicanismo, federalismo.

LEINSDORF

NACIONALISMO FEUDAL ALEMÁN

ARISTOCRACIA ADINEEIRADA

ARISTOCRACIA ADINEIRADA

IMPERIALISMO

ARNHEIM

NACIONALISMO BURGUÉS

CAPITALISMO

COLONIALISMO

IMPERIALISMO

STUMM

NACIONALISMO MILITARISTA

RACISMO

SCHMEISSER

SOCIALISMO

UNIVERSALISMO

FEDERALISMO

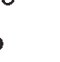

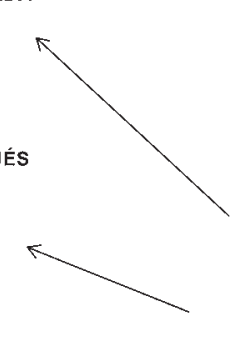

FEUERMAUL

PACIFISMO

COSMOPOLITISMO

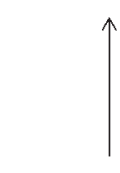

ULRICH (AGATHE)

SEN IDENTIDADE
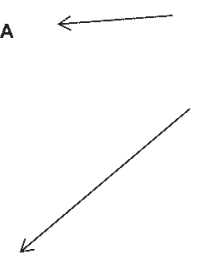

$$
\text { SEN NACIÓN }
$$

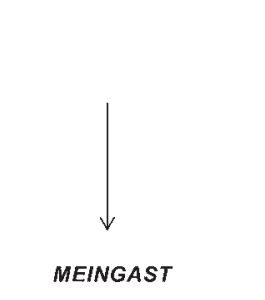

CIDADÁN-SOLDADO
DIOTIMA

NACIONALISMO CULTURAL

BILDUNG

TUZZI

IMPERIALISMO ALEMÁN

BUROCRACIA

ESTATISMO CENTRALISTA
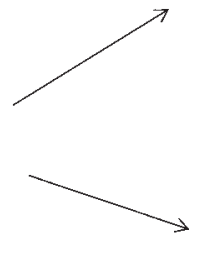

NACIONALISMO LIBERAL

HUMANISMO

MINORIAA XUDAA

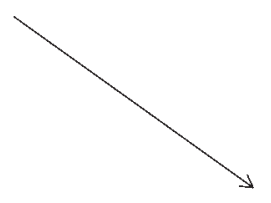

SEPP

RACISMO

ANTISEMITISMO

ANTIHUMANITARISMO

Figura 2: As ideas de nación en $O$ home sen particularidades, de Robert Musil (fonte: elaboración propia de $\mathrm{R}$. Máiz)

Agora ben, confundiriamos por completo o pensamento de Musil sobre a nación se os cáusticos fragmentos de $O$ home sen particularidades-«momentos humanísticos que recordan as relacións entre os riles e a nación»- supuxesen o abandono hipercrítico da idea de nación nas mans das súas formulacións 
organicistas desde o Estado ou contra o Estado. Para estes efectos resultan de grande interese algúns dos seus ensaios posteriores á guerra, sobre todo $A$ nación como ideal e como realidade (1921) e O home alemán como sintoma (1923). Neles substánciase unha crítica do nacionalismo esencialista moi requintada. A experiencia da guerra e a radicalización do nacionalismo alemán conducen a unha elaborada liña de argumentación tendente a dar conta do mecanismo da identidade nacional xerador do belicismo europeo da época (conxuntamente «con Wilson e o cabalo de Troia dos Catorce Puntos»):

$[U] n$ sentimento embriagador de ter por vez primeira algo en común con cada alemán. De pronto, un mesmo convertíase nunha partícula, humildemente disolvida nun acontecer suprapersoal [überpersonlihes Geschehen], e, ao seu acubillo, sentíase a nación como algo en verdade corpóreo, coma se unhas características ancestrais e místicas que permaneceran dormentes durante séculos espertasen de pronto [...], e millóns de seres humanos correron de repente, engaiolados, a morrer pola nación. (Musil 2000: 1060)

Musil explora criticamente e polo miúdo o concepto substancialista de nación baseado na raza: a xeneralizada «confusión entre o concepto de nación e o de raza», segundo a cal se produciu «a terxiversación teolóxica que leva a afirmar que o ser humano está constituído pola súa raza [...]; precisamente, boa parte do noso idealismo nacional consiste nesa enfermidade do pensamento» (Musil 2000: 1064). Nos seus ensaios dos anos vinte, Musil insiste de xeito reiterado na conexión política entre nacionalismo organicista, a nación concibida como unha unánime totalidade orgánica a partir da «fronteira interior» (Fichte) entre nós/eles, propiolalleo, amigo/inimigo, e racismo, militarismo e guerra:

O pensamento alemán descansa quer sobre fantasías raciais, quer sobre unha filosofía do sacrificio no nome desa suma de sumas que é o Estado, nunha idea de pecado orixinal que soamente pode redimirse mediante a fusión coa totalidade $[\ldots]$ nunha masa xigantesca [...]. Esa nada sen sentimentos, ideas nin decisións, aínda que non é a nación, é, así e todo, a substancia que a mantén viva [...]. Un «nós» que non se corresponde coa 
realidade. «Nós, os alemáns», tal é a ficción dunha suposta comunidade. Pero o verdadeiro "nós» é este: nós non somos nada os uns para os outros ["wir sind einander nichts»]. (Musil 2000: 1070; cursiva de R. Máiz)

Desde esta perspectiva, a nación devén hipostasiada como un suxeito colectivo que engole os individuos e procede non soamente á súa proxección exterior como anexión, guerra etc., senón que ademais se prolonga cara ao interior na ablación do heteroxéneo do seo do pobo, na procura da prístina pureza dun suxeito colectivo dotado dun destino predeterminado: «O nacionalismo é só un caso particular de nostalxia forzada dunha Fe [...]; certamente o ser humano pode atopar acubillo no seo dunha comunidade. Pero a comunidade que é unha nación, baseada e pechada en si mesma, xa non ten ese apoio que ofrecer [...] e procúrao nunha dimensión subxacente, na raza, na relixión» (Musil 2000: 1363).

Esta crítica da nación orgánica, versión Blut und Boden, non implica, así e todo, que Musil a extrapole nun rexeitamento da idea de nación tout court. En efecto, retomando o fío da "posibilidade de sermos outramente» (anderer Zustand), tamén a identidade nacional, como acontecía coa subxectividade individual, posúe infinitas posibilidades de articulación política, e Musil explora este vieiro co mesmo procedemento deconstrutivo/construtivista, agora a respecto da «nación» no canto do «eu». Tamén aquí se dá un tránsito «desde o colapso dunha tradición unificada á exploración de formas emerxentes na cultura moderna» (Luft 1980: 235), se tenta superar o momento da pura negatividade, do gar Nichts, da nada máis absoluta, na procura aberta e continxente de «satisfacer as esixencias de univocidade sen sacrificar a multiplicidade».

O punto de partida é «a ousadía de postular o sentimento nacional como “cuestión"», criticar a nación en canto «ideal» sobredeterminado como comunidade substancial, para esculcar as dimensións políticas e culturais que están no fondo do fenómeno nacionalitario; isto é, desbotar unha simple fuxida da idea de nación para debruzarse no cosmopolitismo universalista, procurar «unha mera moral da civilización que renuncie ao fermoso atavismo da Kultur» (Musil 
2000: 1072), deixando na man dos nacionalismos racistas e antisemitas a hexemonía da identidade nacional. En efecto, ao ver de Musil, «aqueles para quen a nación sinxelamente non existe presupóñeno con demasiada facilidade» (Musil 2000: 1060). Pero moi outra é a lección da guerra: «O ser humano revelouse como unha masa sorprendentemente máis manipulable do que se adoita supoñer» (Musil 2000: 1045), unha sorte de masa líquida, que vive nun «estado non vectorial» (ungerichteter Zustand), aquel «desanimado mesturarse como partículas de ferro nun campo non magnetizado», e na febril procura dun «eu» colectivo, de afundirse nunha masa que lle subministre sentido, punto de referencia nun mundo marcado pola incerteza. «Falando con precisión, a nación é unha fantasía [Einbildung] en todas as versións que se ofreceron dela» (Musil 2000: 1071), pero esta Nación imaxinaria non ten como única posibilidade devir un Ideal cristalizado na procura de rochosos fundamentos, dunha terra firme, «das feste Land», que dicía Herder, na que facer pé ante a crise moderna da subxectividade, na procura de «firmes puntos de referencia». Pola contra, hai outra posibilidade, sobre a que Musil dubida, entre confianza e desesperación, ao longo de toda unha vida transitando entre dúas guerras, a saber: «Ao concepto de nación non se lle recoñeceu o seu carácter instituínte, como algo que habería que producir, senón que resulta considerado como algo xa instituído, que xa existe». Ao contrario, «a conciencia do que está a suceder esixe que xa non se trate a nación nin o Estado como "Ideais" absolutos, senón como obxectos que teñen que responder á súa finalidade». En canto Ideal, isto é, repleta de sobresignificacións holísticas, metafísicas, biolóxicas ou burocrático-militaristas, a «Nación», pero tamén o «Estado» ou o «Pobo», están «caducos». Porén, en canto conceptos políticos, «cómpre miralos como preguntas e non como respostas; non ver neles substratos fondos dos fenómenos, senón fenómenos sociais complexos; consideralos non puntos de partida, senón resultados sociolóxicos; noutros termos, como produtos e non como produtores» (Musil 2000: 1366).

Velaí o agromar dunha eventual identidade nacional «outra», asumida non como unha esencia inconsútil, predestinada á limpeza étnica e á guerra, senón como 
un proceso continxente, aberto e indeterminado, aquel Prozess des Werdens que diría Bauer naquela altura (Bauer 2020: 154). De aí a posibilidade política doutra síntese, doutra articulación democrática e pluralista da identidade nacional. Esta é a razón de que Musil defenda a necesidade política da «ideoloxía», necesaria para acadar un mínimo de "coherencia subxectiva», pero tamén cara á creación daqueles «vínculos que sustentan a vida dos seres humanos», sen os cales ficaría como un ser «amorfo», asocial e patolóxico. A eventual posibilidade, en definitiva, de pasar dunha subxectividade esnaquizada a unha identidade compartida, pluralista e desracializada.

Tal é a resposta musiliana á Ichlosigkeit da modernidade que se prolonga na Heimatlosigkeit do Finis Austriae: a extraterritorialidade (Exterritorialität), a lucidez de «procurar elementos de valor naquilo que nos horroriza» (Casals 2015: 659), desde aquela condición de «apátrida e políglota à tout faire», como a do protagonista de $A$ morte do meu irmán Abel, de Gregor von Rezzori. Para Musil, tan falsa resulta a saída da busca de fundamentos sólidos da identidade na raza ou a nación como a aceptación resignada e cínica da fragmentación e o peche de horizontes. Na procura dunha «ética» como apertura atemporal continxente doutras posibilidades, o noso autor desenvolve unha perspectiva construtivista que o priva de atopar acubillo, tamén de calquera consolo subxectivo (como «autor») ou comunitario (como «austríaco», como «alemán»). Lou Andreas-Salomé expresara con desolada lucidez o alto custo persoal desta rara teima «anacional» (unnational) nunha evocadora carta de 1924 («Abril») a Rainer M. Rilke, escrita cando este xa falecera, que ben podería estar dedicada a Musil:

Agora que nós, os alemáns, nos vemos confrontados politicamente á cuestión do nacionalismo, pregúntome até que punto non sería fatal para o teu destino que sentises tan forte antipatía pola túa condición de austríaco. Cabe pensar que unha patria, amada de modo primario -a comunidade do sangue-, te protexería das angustias [...], da condena de ti mesmo. No chan da patria [Heimat], coas súas pedras, as súas arbores, hai algo sacrosanto que chega até o interior mesmo do noso ser. (Wiesenthal 2015: 1038) 
Alén de Leopold Bloom no Ulysses de Joyce, naquela súa tentativa improbable de reconciliar a identidade xudía e a irlandesa (Lewis 200: 48), Musil procura, na mesma plasticidade dos seres humanos que facilita a súa manipulación belicista e racista, unha eventual posibilidade de acubillar cultural e democraticamente a plurinacionalidade, paralela á buscada no ámbito das ciencias sociais por austromarxistas como Renner e Bauer (Máiz e Pereira 2020). Posibilidade, por cabo, dobremente fracasada tanto na guerra do 14 como no posterior ascenso do nazismo e a II Guerra Mundial, mentres Musil, en penosas condicións económicas, seguía a pelexar coa novela infinita no seu tema de sempre: «a soidade que desesperou de poder chegar nunca a ser acolledora» (Cacciari 2004: 87). Dicía Canetti, anos despois, na súa lembranza: «Toute courtoisie lui semblait suspecte [...]. Il ne se sentait pas "déplacé" en temps de Guerre [...] [:] il y voyait une confirmation de lui même» (Canetti 1983: 656). Nado en Klagenfurt, nin checo nin alemán nin austríaco, estudante e cidadán itinerante en Eisenstadt, Brno, Bruxelas, Berlín e Viena, refuxiado en Xenebra, cun público lector maiormente xudeu, Musil érguese, con xenial desmesura, como a máis alta e atormentada expresión literaria daquela condición extraterritorial emerxente na época da Europa de entre as guerras á que se refería Bauer: «pouco querido e pouco de fiar, en tempos de loitas nacionais sospeitoso de traidor e tránsfuga» (Bauer 2020: 315). 


\section{REFERENCIAS BIBLIOGRÁFICAS}

BAUER, Otto (2020): La socialdemocracia y la cuestión de las nacionalidades, ed. de Ramón Máiz e trad. de Pedro Piedras, Madrid, Akal (versión orixinal [1907]: Die Nationalitätenfrage und die Sozialdemokratie, Wien, Ignaz Brand).

BAYÓN, Fernando (2009): Filosofía y leyenda: variaciones sobre la última modernidad (de Tolstói a Musil), Barcelona, Anthropos.

BLANCHOT, Maurice (1959): Le Livre à venir, Paris, Gallimard.

BöHME, Hartmut (1974): Anomie und Entfremdung, Regensburg, Scriptor Verlag.

BRINGAZI, Friedrich (1998): Robert Musil und die Mythen der Nation, Berlin, Peter Lang.

Broch, Hermann (1980): La muerte de Virgilio, ed. de J. M. Ripalda, Madrid, Alianza.

Broch, Hermann (1984): Hugo von Hofmannsthal and His Time: The European Imagination, 1860-1920, Chicago, University of Chicago Press.

Broch, Hermann (2016): Los sonámbulos, Barcelona, Debolsillo.

BÜrger, Christa / Peter BÜrger (2001): La desaparición del sujeto, Madrid, Akal.

CACCIARI, Massimo (1980): Dallo Steinhoff: prospettive viennesi del primo Novecento, Milano, Adelphi.

CACCIARI, Massimo (2004): Soledad acogedora: de Leopardi a Celan, Madrid, Abada.

Canetti, Elias (1983): «Mémoire de Robert Musil», en Jean Clair (ed.), Vienne 1880-1938 : l'apocalypse joyeuse, Paris, Centre Georges Pompidou.

CASALS, Josep (2003): Afinidades vienesas, Barcelona, Anagrama.

CASALS, Josep (2015): Constelación de pasaje, Barcelona, Anagrama.

Clair, Jean (ed.) (1983): Vienne 1880-1938 : l'apocalypse joyeuse, Paris, Centre Georges Pompidou.

FеJTÖ, François (1990): Réquiem por un imperio difunto: historia de la destrucción de Austria-Hungría, Madrid, Mondadori.

FranK, Manfred (2004): Dios en el exilio, Madrid, Akal.

GAY, Peter (2002): Schnitzler y su tiempo, Barcelona, Paidós.

HickMan, Hannah (1991): Robert Musil and the Culture of Vienna, La Salle, IL, Open Court.

Hinz, Michael (2000): Verfallsanalyse und Utopie: Nietzsche-Rezeption in Thomas Manns "Zauberberg" und in Robert Musils "Der Mann ohne Eigenschaften", St. Ingbert, Röhrig Universitätsverlag.

JANIK, Allan / Stephen E. Toulmin (1973): Wittgenstein's Vienna, New York, Simon \& Schuster.

JonsSON, Stefan (2000): Subject without Nation: Robert Musil and the History of Modern Identity, Durham, Duke University Press.

Kristeva, Julia (1974): La Révolution du langage poétique, Paris, Seuil.

Latraverse, François / Walter Moser (eds.) (1988): Vienne au tournant du siècle, Paris, Albin Michel.

LEWIS, Pericles (2000): Modernism, Nationalism, and the Novel, Cambridge, Cambridge University Press.

LuFT, David S. (1980): Robert Musil and the Crisis of European Culture, Berkeley, University of California Press.

LUKÁCS, György (2016): Teoría de la novela, Barcelona, Debolsillo.

MAGRIS, Claudio (1963): Il mito absburgico nella letteratura austriaca moderna, Torino, Einaudi.

Magris, Claudio (1971): Lontano da dove: Joseph Roth e la tradizione ebraico-orientale, Torino, Einaudi.

MAGRIS, Claudio (1982): Itaca e oltre, Torino, Einaudi. 
Márz, Ramón (2007): «La nación como horizonte de lectura», en Ramón Máiz (ed.), Nación y literatura en América Latina, Buenos Aires, Prometeo, 9-17.

MÁrz, Ramón / María Pereira (2020): «Otto Bauer: the idea of nation as a plural community and the question of territorial and non-territorial autonomy", Philosophy and Society, 31:3, 287-300.

MarramaO, Giacomo (1977): Austromarxismo e socialismo di sinistra fra le due guerre, Milano, La Pietra.

MarTens, Gunther (2006): Beobachtungen der Moderne in Hermann Brochs Die Schlafwandler und Robert Musils Der Mann ohne Eigenschaften: rhetorische und narratologische Aspekte von Interdiskursivität, München, Wilhelm Fink.

Molnár, Miklós / André Reszler (eds.) (1989): Le Génie de L'Autriche-Hongrie : État, société, culture, Paris, PUF.

Morgenstern, Soma (2000): Huida y fin de Joseph Roth, Valencia, Pre-Textos.

MuÑoz, Jacobo (1994): prólogo a Robert Musil, Diarios 1899-1941/42, 2 vols., València, Alfons el Magnànim.

Musil, Robert (1994): Diarios 1899-1941/42, 2 vols., València, Alfons el Magnànim.

MusiL, Robert (2000): Prosa und Stücke, Hamburg, Rowohlt.

MusiL, Robert (2010): El hombre sin atributos, 2 vols., trad. de Pedro Madrigal, José María Sáenz e Feliu Formosa, Barcelona, Seix Barral / Austral (versión orixinal [(1978) 2003]: Der Mann ohne Eigenschaften, 1: Erstes und zweites Buch, Hamburg, Rowohlt).

REZzORI, Gregor von (1993): Un armiño en Chernopol, Barcelona, Anagrama.

Ricceur, Paul (1990): Soi-même comme un autre, Paris, Seuil.

Rogowsky, Christian (1994): Distinguished Outsider: Robert Musil and His Critics, Columbia, SC, Camden House.

Rотн, Joseph (1998): Fuga sin fin, Barcelona, Acantilado.

Roth, Joseph (2020): La marcha Radetzky, Barcelona, Alba

Schorske, Carl E. (1979): Fin-de-siècle Vienna: Politics and Culture, New York, Knopf.

Timms, Edward (1986): Karl Kraus: Apocalyptic Satirist: Culture and Catastrophe in Habsburg Vienna, New Haven, Yale University Press.

Valverde, José María (1990): Viena, fin del Imperio, Barcelona, Planeta.

Wiesenthal, M. (2015): Rainer Maria Rilke (el vidente y lo oculto), Barcelona, Acantilado. 